\title{
Restoration Ecology
}

\author{
BOOK REVIEW
}

\section{Ecological Restoration}

Susan M. Galatowitsch. 2012. Sinauer Associates, Sunderland, Massachussetts, USA, 630 pages, 345 illustrations, \$89.95 (casebound). ISBN: 978-0-87893-607-6. Also available as Ebook.

There is growing recognition of ecological restoration as an international priority; for example Target 15 of the 2010 Convention on Biological Diversity aims for "restoration of at least $15 \%$ of degraded ecosystems" globally. And large-scale multi-million dollar ecological restoration projects have been launched in many countries in recent decades. Typically these initiatives are accompanied by hugely optimistic aspirational statements, which sadly often fall short when it comes to implementation, although this achievement shortfall is rarely documented because the planning and budget did not allow for systematic monitoring of outcomes. The need to reverse environmental degradation is placing demands on the science and the art of ecological restoration that often exceed their capacity to deliver workable or soundly costed solutions.

Ecological restoration is developing rapidly as a practice alongside its twin, restoration ecology as a field of science. But they often spin in separate universes. By comparison with a more fully developed practice such as medicine, ecological restoration lacks a strong evidence-based foundation, rigorous training, and accreditation processes. Yet it is increasingly expected to deliver ambitious outcomes. As in medicine, the imperfect practice of the craft can nevertheless deliver new information which advances the science. To meet the environmental needs of the 21 st century, restoration ecology will need a new cohort of workers trained in both science and practice. They need to be literate in biophysical and ecological concepts and measurements, capable of handling electronic systems for managing spatial and other data, and to be critical and creative thinkers. They also need the ability to navigate a maze of government, NGO and community interactions, and to deal with project economics, financial management and bureaucratic reporting.

To help train them we will need new university courses and suitable textbooks, reaching far beyond the current offerings. The academic community is beginning to gear up for this effort, and this new textbook by Susan Galatowitsch is an excellent step in the right direction. Many new books about restoration have been published in recent years. Previous publications, and especially the Island Press series, have conveyed new information and perspectives at the field's cutting edge. However these books have tended to focus on the perspectives of individual authors writing in their selected restoration subfields, or to target particular ecosystem types or geographical regions. Their content and style of delivery is useful mainly to researchers, graduate students, and trained practitioners. For basic training of undergraduate students or entry-level practitioners we need educational materials which seek to stand back from the detail of current research and extract the most important principles, ideas and generalisations across a wide range of aspects of restoration ecology and diverse biogeographical 
contexts. Such materials also need to express sometimes complex ideas in plain language, recognise and define jargon when appropriate, and illustrate ideas and applications with well-chosen examples.

Galatowitsch's book achieves that goal. It sets an agenda for restoration education at undergraduate university level, because it is a true textbook suitable for basic training, in terms of scope, writing style, and presentation. In scope it makes an effort to cover the field rather than engaging selectively with particular perspectives. And it's a large and diverse field to cover. In general, the decisions about what to include and what to omit have been sensibly made. I was impressed by the balance between breadth of scope and depth of treatment. In tone the written text is usefully didactic, while avoiding being prescriptive or evangelistic (which can be unfortunate tendencies in some ecological restoration writing). The writing style has a good level of readability, and uses an engaging narrative approach. Ideas are, in general, clearly explained, and there is frequent use of examples to aid comprehension. There are numerous diagrams and photographs, which have been well chosen to amplify and complement the text. Each Chapter ends with a point-list summary, and a set of questions to challenge student comprehension. The latter will also be useful to teachers.

Because the focus is ecological restoration rather than restoration ecology, this book deals with the scientifically-informed practice rather than the science alone, and includes two chapters focused on the project management and human dimensions of this field. The science content is packed full of technical detail but avoids the cookbook approach. The content ranges across terrestrial, freshwater and marine ecosystems and across population, community and ecosystem levels. Abiotic properties, flora and fauna are all given due weight. General principles which apply across ecosystem types are drawn out, while important issues specific to these ecosystems are also clearly presented. The content is up to date (relative to the publication year, 2012), and incorporates current ideas about issues such as climate change, landscape-scale approaches and the role of monitoring and adaptive management.

The book is organised in three parts. An interesting and effective aspect of its organisation is the way in which the text throughout Parts 1 and 2 draws upon profiled case studies from Part 3 in order to more fully flesh out the general issues.

Part I (Restoration Process) is a general treatment of component properties of ecological restoration, comprising five Chapters: introduction; diagnosis and goal setting (a substantial part of which outlines key ecological concepts); planning; social and institutional support (which focuses on the social and administrative processes involved in restoration projects); and monitoring and evaluation. This section provides a sound context for planning and implementing ecological restoration projects of all types.

Part 2 (Restoration Approaches) outlines relevant background information about attributes whose states or values are frequently altered during abiotic or biotic degradation, together with descriptions and examples of practical approaches to their restoration. Component chapters are: landforms and hydrology; soil and water quality; plants; invertebrates; and vertebrates. The scope of practical detail ranges across (but is not limited to) issues such as methods of slope stabilization, remediation of aquatic eutrophication or toxic pollution, seed collection and planting methods, species' translocations and reducing habitat fragmentation.

Part 3 (Restoration Cases) presents concise but informative individual profiles of 19 diverse restoration case studies, covering projects such as Sweetwater Marsh and Sargent's cherry palm in north America, the Great Barrier Reef marine park in Australia, the Skjern river in Europe, Baghmara community forest in Asia, and a forest corridor project in South America. Collectively they span all 
continents worldwide. All the case studies are long-term in nature, and their descriptions draw on reference to scientific and management publications, which are listed at the end of each case. Cases are also usefully cross-referenced to the sections within Parts 1 and 2 where they are discussed further, to aid linking of broad concepts to the details of specific projects.

Relatively, my criticisms are minor, and some relate to issues that could be difficult to avoid given the state of current knowledge. First, there is (by design) negligible discussion of the role of economic issues in ecological restoration, and this leaves a gap in overall coverage. I would hope that this could be at least partially remedied in any future editions. Second, apart from availability in e-book format, there seems to be negligible engagement with web resources or e-technology. Third, the narrative style means that it can be difficult to dip into this book to rapidly access information about specific issues. The index, although extensive, has not been designed to handle the unstable terminology in this field, which means that it is necessary to search for pages using a series of alternative words (which could be beyond the vocabulary of a learner). For example the concept and importance of "trophic cascades" is described in Part 1 (p. 53); but any link with the closely related process of "hyperpredation" as described in Part 2 (p. 396) turns up in the index under "trophic interactions", and neither of these lead the reader to the description of cascading impacts of overfishing the predators of reef-damaging crown-of-thorns starfish in Part 3 (p. 351). The difficulty of rapidly extracting information by someone who "dips" rather than reads could perhaps be remedied by more comprehensive indexing, by listing of related terms in the glossary, and/or by including a "key terms" section at the start of each chapter (a device used in some ecology textbooks).

This book will be useful to teachers and students of restoration in educational programs at all levels. It is also a worthwhile addition to the personal library of any practitioner or researcher who would like to have an accessible overview of the current state of this field. Students in particular will welcome its availability in the less expensive e-book format. Competing texts are likely to emerge in the future (no doubt some are currently in gestation), and time will tell if students themselves deem this one to be a valuable learning tool, but at least for now this book sets a new performance bar in education for ecological restoration.

Carla P. Catterall

Griffith School of Environment, Griffith University, Australia E-mail: c.catterall@griffith.edu.au 